\title{
Teaching Wellness in a College Physical Education Course: Pre/Post Outcomes over the Semester
}

\author{
John Lothes II, LPA, Ed.D. \\ University of North Carolina Wilmington \\ School of Health and Applied Human Sciences
}

\begin{abstract}
Background: Over the years, college student wellness has become an issue of concern. This study reports the results that physical education classes and effects they on college student overall wellness over the course of a semester.

Aim: This study examines the pre/post outcomes of a physical education course on 12 dimensions of wellness from the start of the semester to the end of the semester.

Methods: College students $(N=1,497)$ taking a PED101 were assessed at the beginning (pre) and end (post) of the semester for wellbeing outcomes according to the Wellness Inventory. Quantitative outcomes from the Wellness Inventory were compared pre/post as well as demographic variables (e.g., gender and health status).

Results: All 12 dimensions of wellness showed increases from the start of the semester to the end of the semester. The results found statistically significant changes between the pre and post assessments for all dimensions of wellness outcomes. There were also significant changes between the pre and post assessments when investigating differences based on sex and health status.
\end{abstract}

Conclusion: PED101 courses can be useful interventions to help move college students towards wellness.

Submitted 10 October 2019: accepted 12 November 2019

Keywords: health education, college student health, wellness, wellness inventory

Research indicates that positive subjective wellbeing serves as a protective mechanism for health. Wellbeing research has clearly established a relationship between impaired wellbeing and negative psychological symptoms, premature mortality, heart disease, disability, and other chronic disorders (Lyubomirsky, King, \& Dier, 2005; Steptoe, Deaton, \& Stone, 2021). There is an inverse relationship between higher levels of wellbeing and physical and mental health problems, missed workdays, and suicide risk. Positive subjective wellbeing is associated with longevity, productivity at work, and increased relationship health (Keyes et al., 2012; Keyes \& Grzywacz, 2005; Keyes, \& Simoes, 2012). This study examines how a semester long Physical Education (PED101) class may play a role in increasing wellbeing in college students.

The biopsychosocial model (Engel, 1977; 1980) was first proposed as an expansion on the medical model that existed at the time. The medical model focused more on physical wellbeing while the biopsychosocial mode argued for a holistic view of a person. Later, there was also a recommendation that the biopsychosocial model also include an incorporation of spiritual aspects as well (Gordon, 1990).Travis and Ryan (1981; 2004) developed the Wellness Inventory to assess wellness on 12 dimensions: Selfresponsibility \& love, breathing, sensing, eating, moving, feeling, thinking, playing \& working, communicating, intimacy, finding meaning and transcending. The Wellness Inventory captures a snapshot of the recommended biosocial model and the recommended expansion of issues of spirituality (Gordon, 1990) by including scales that assess Finding Meaning and Transcending. 
Travis first proposed a wellness continuum in 1977 and this has continued to evolve with current theories (Edelman \& Mandle, 2017) of wellness.

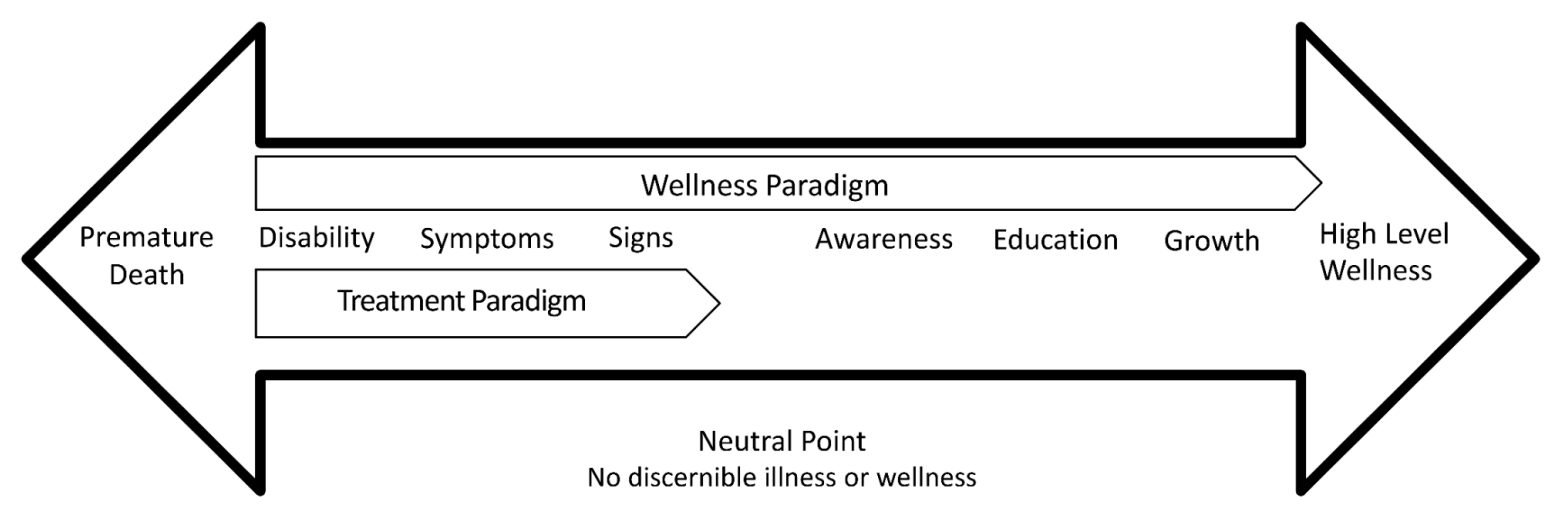

Figure 1. Illness-Wellness Continuum (Travis, 1977).

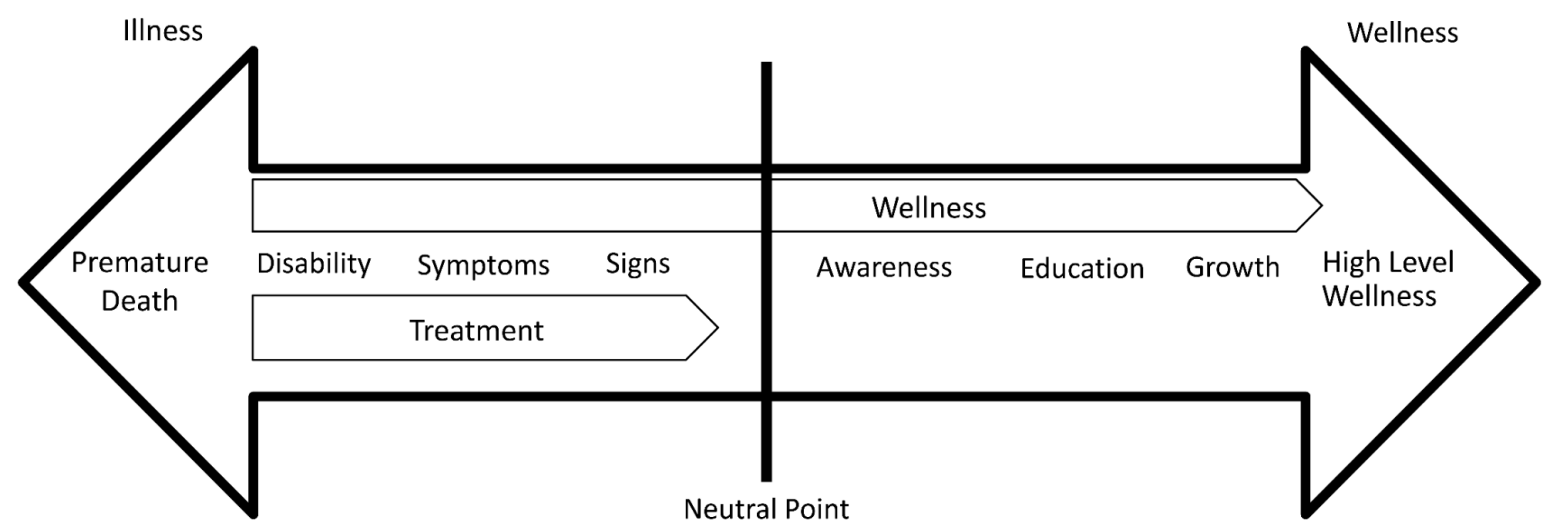

Figure 2. Continuum of Wellness (Edelman \& Mandle, 2017).

College student wellness has been a growing focus of recent researchers (Burris, Brechting, Salsman, \& Carlson, 2009) as they attempt to understand what factors play a role in student health and wellbeing (Wahl-Alexander \& Chomentowski, 2018). Some researchers have examined demographic variables (Burri et al., 2009; Lothes \& Nanney, 2019) to see which ones may be associated with higher rates of wellness or illness. With the continued trend for college students to engage in sedentary (Buckworth \& Nigg, 2004) and unhealthy behavioral patterns, universities need to design and employ effective ways to encourage students to engage in activities that promote wellness. As college represents the formative years for developing health behavior patterns (American College Health Association [ACHA], 2010) it would be wise for researchers to head the call to action (Cardinal, 2014) to start to not only study student wellbeing, but to also examine how we can have an effect on students health and wellbeing beyond that of teaching about diet and exercise. One of these approaches has been the holistic approach to wellness (Gieck, \& Olsen, 2007). Hettler (1984) proposed a holistic approach that consisted of six broad dimensions of health-related behaviors: Physical wellness, emotional wellness, spiritual wellness, social wellness, occupational wellness, and intellectual wellness. Promoting a holistic approach to wellbeing has been associated with improved psychological functioning and serves as a protective mechanism against physical disorders (Gieck, \& Olsen, 2007).

Gieck and Olsen (2007) offered bimonthly classes to college students over a 10-week period. During this study, they encouraged weekly walking activities (tracked by a pedometer) and the students attended five classes throughout 
the study on topics related to wellness: (1) general principles of holistic wellness, (2) physical wellness, (3) nutrition/healthy eating, (4) spiritual and emotional wellness, and (5) hydration and stretching.

At the start of each class, study participants completed a posttest measure to assess how much they had learned from the previous class. Study participants maintained and would turn in a steps log for the previous two weeks. The participants also completed a pretest measure to assess their level of knowledge about wellness information to be taught on that day's class. They completed a review of the topic at the end of each class and offered a group discussion about how students can integrate what they had learned during the presentation into their daily lives. At the end of each class, study participants designed a behavior plan in which they would map out details of behaviors and activities that they could then use to incorporate the concepts of holistic wellness into their daily activities for the subsequent two weeks before returning for the next class.

Results of this study showed that knowledge of holistic wellness significantly increased from start of the study to end of the study for participants. Body fat percentage and mean body mass also showed significant decreases from start of the study to the end, however BMI did not show any significant changes. Frequency of resistance training, general exercise, and daily number of steps show significant increases from the start of the study to the end of the study.

While this study suggests that encouraging physical activity and teaching about matters of holistic wellness may lead to increases in activity and knowledge base, the reliability of the findings are limited given the relatively small sample size $(N=15)$. Further, the moderating effect of gender cannot be overlooked given the differential drop out of all males rendering results generalizable to female students only. While this study sheds light on the potential for how teaching about wellness and encouraging movement can increase these factors, it does not tell us how this may be accomplished with larger numbers of students and if these effects will also hold true with males. As these researchers stated, all male participants that were recruited dropped out of the study after the first class. The current study addresses these issues by sampling a much larger number of students $(N=1,497)$ that includes male participants.

Lothes and Nanney (2019) conducted an end of semester assessment with college students $(N=1,544)$ using the Wellness Inventory and found demographic variables, such as age and sex, did not show moderating effects on the 12 dimensions of wellness measured by Travis's Wellness Inventory. However, self-reported health status and frequency of exercise showed significant differences on all 12 dimensions of the Wellness Inventory. Students who reported excellent or good health had higher ratings of wellness than students reporting to be in fair or poor health. Students that reported exercising more frequently (daily, 4 - $6 \mathrm{x}$ week, $3 \mathrm{x}$ week) also reported significantly higher ratings of wellness than students who reported exercising less frequently ( 2 x week, 1 x week \& 1 x month or less) on most dimensions. Lothes and Nanney's (2019) study indicated that age and sex may not be as important factors in wellness as are health status and frequency of exercise. However, they did not examine pre/post scores to see if there are difference between these groups at the beginning or the end of the semester, or to see if these groups also show changes across the semester when assessed by the wellness inventory. This is welcome news for health educators and researchers since frequency of exercise and health status are easier to control or manipulate than age and sex. Lothes and Nanney (2019) provide insights into wellness inventory outcomes with college students by demographic categories, however they are missing insight into whether wellness can be enhanced through specific physical education interventions.

Another study (Baldwin, Towler, Oliver, \& Datta, 2017) examined the difference of wellness factors between liberal arts college students and students attending a research university. In this study the researchers examined 5 
factors of wellness: Physical, emotional, social, intellectual, and occupational between liberal arts college students ( $N$ $=126)$ and students attending a research university $(N=85)$. Carnegie classification was given for an operational definition of "research university" for this study. The researchers recruited 211 students between both colleges and administered surveys assessing different scales of wellness. They found that there were significant differences between employed and unemployed students on ratings of wellness, where employed students had higher ratings of selfefficacy than the unemployed students, and the employed students also reported a significantly lower frequency of exercise than the unemployed students. The results also showed some sex difference where female students reported engaging in less physical activity and lower overall health related behaviors than male students. While this study does shed light on wellbeing differences between college students, like Lothes and Nanney's (2019) study, it only reveals a onetime assessment without providing any insight into possible interventions that could be adopted to encourage college students and enhance these factors of wellbeing. The current study seeks to expand on this gap in the literature where studies are examining differences between demographic variables in the absence of possible interventions for change.

Other researchers (Prilleltensky et al., 2015; Cardinal, Park, Kim, \& Cardinal, 2015) have called for a multidimensional approach to examining wellbeing. In this study, outcomes from a university physical education class using the Wellness Inventory was used to assess 12 dimensions of wellness in college students from the beginning of the semester to the end of the semester. Cardinal (2014) has issued a "call-to-action" of educators and researchers to attract and keep people more physically active across the lifespan. While the focus of this study was not physical activity alone, it did heed this call to action by Cardinal about trying to help college aged individuals find a path to wellness across their lifespan.

Health behavior patterns established in college have been shown to correlate with mid-life health behavior patterns (Hultquist, Duckham, Stinson, \& Thompson, 2009). As health educators it is our mission to try and help students establish healthy lifestyle choices while learning to implement strategies to combat unhealthy lifestyle choices through education. Rouse and Biddle (2009) argue that better education in regard to physical activity and monitoring can play a pivotal role in helping to encourage students to move towards wellness. The American College Health Association $(2010$; 2018) has identified physical inactivity as a continued concern for this population and has called for immediate attention on the matter. Alarmingly, an increased number of college students are adopting sedentary and unhealthy lifestyles during this stage of life (Keating, Guan, Pinero, \& Bridges, 2005). While in college, students are learning to balance work, school, relationships, free time, and self-care, maybe for the first time on their own. Providing education on wellbeing to students is vital at this stage of development. Through effective and quality education we can teach students about the effects of effective health habits on wellbeing. Because there are many factors that play a role in college students' wellbeing (Downes, 2015), it would be wise to take a multidimensional approach to wellness (Travis \& Ryan, 2004).

Myers and Sweeney (2004) proposed an evidence based multidimensional model that is based on characteristics of healthy individuals and focuses on a strength-based, choice oriented model of wellness that is grounded in theory. They argue that this modeling can be used with or without assessment tools to help understand different components of wellness, the interaction of these components and the manner in which positive change may be facilitated. In their literature review the authors discuss different wellness models and possible influences into one's wellness. One theoretical model they discuss is that of the Wheel of Wellness and how its 12 components of wellness which include factors such as; family, spirituality, education, business, government and community influence behavior. The authors 
of this study were able to identify societal factors that played a role in wellness such as community and government while overlooking those factors over which an individual may exercise greater control. While Travis (1981; 2004) argues that we can help shift individuals from directions of illness (weaknesses) to directions of wellness (strengths) by focusing on factors that individuals may have more control over in his 12 dimensional model.

Travis $(1981 ; 2004)$ argues that wellness is a process and is not a static state. While many assume the absence of illness means wellness, Travis (2004) argues this is not the case. He believes there are varying degrees of both illness and wellness. The Illness-Wellness Continuum is a graphic representation of illness and wellness. In this model an individual can move past the neutral point to either higher degrees of illness or wellness. In the Illness-Wellness continuum it is possible to not have physical symptoms but experience depression, boredom, anxiety, or unhappiness. As a result of continued experience of these negative emotions, an individual may develop physical and mental health symptoms. High levels of wellness involve self-care activities that may include such things as taking care of oneself physically, effectively experiencing and expressing oneself emotionally, using one's mind constructively, being creative and spiritual. Travis argues that wellness is not so much about where a person stands on the continuum, but whether that individual is facing toward wellness or toward illness.

Moving from the center to the left indicates a progressively worsening state of wellbeing. Moving to the right of the continuum indicates increasing levels of health and wellbeing. The treatment paradigm as proposed by a medical model (Kirsten, Van der Walt, \& Viljoen, 2009) postulates that drugs, surgery, and psychotherapy can bring people to a neutral point, where symptoms of disease have been reduced or eliminated. The medical model falls short as a robust wellness theory by ending here. While the wellness paradigm, which can be used at any point on the continuum, assists in moving individuals towards a higher level of wellness. The wellness paradigm encourages individuals to move as far forward toward wellness as possible. Of primary interest for this study was that of the college student population and helping direct participants towards wellness and away from illness.

According to the U.S. Department of Health and Human Services (DHSS, 2019) adults should be moving more and sitting less throughout the day. They advise that adults that engage in some form of moderate to vigorous physical activity will gain some health benefits. The DHSS recommends that adults engage in at least 150 minutes to 300 minutes of moderately intense exercise every week, or 75 minutes to 150 minutes of vigorously intense exercise every week, or, a combination of both moderate and intense exercise throughout the week. It is also recommended that adults engage in a combination of both aerobic exercise and some form muscle-strengthening activities two or more times a week. The World Health Organization (WHO, 2010) recommends that adults 18 - 64 years old should engage in at least 150 minutes of moderate intensity aerobic physical activity or engage in at least 75 minutes of vigorously intense aerobic physical activity throughout the week, or some form of a combination of both moderate and vigorously intense exercise throughout the week. College level physical education courses can provide a platform to shape young adults toward more wellness-related behaviors as suggested by the DHSS and the WHO.

The purpose of this study was to determine if there were changes in wellness from Physical Education (PED 101) courses at a university in the southeast United States (IRB approval \#18-0232). An examination of overall changes in the 12 dimensions of wellness was conducted, as well as examining differences in the demographic variables of sex and self-reported health status. Different demographic variables were assessed to gauge whether there were differences in the 12 wellness outcomes for college students at the post-assessment phase. The Wellness Inventory (Travis, 2004) was used to assess students at the beginning (pre) and end (post) of the semester on 12 dimensions of wellness. 
The Following Hypotheses guided this study:

$\mathrm{H}_{1}$ : There are statistically significant changes in all 12 dimensions of wellness from the start of the semester to the end of the semester for all students combined.

$\mathrm{H}_{2}$ : Males and Females will show statistically significant increases in wellness dimensions from start of the semester to the end of the semester.

$\mathrm{H}_{3}$ : There is a statistically significance difference in wellness outcomes between participants who self-reported being in an excellent or good health status compared to those who self-reported as being in a fair or poor health status.

$\mathrm{H}_{4}$ : There is a statistically significant difference between pre outcomes and post outcomes within all health status groups

Although no hypothesis was presented, exploratory data analysis will also be conducted to see if study center materials on the Wellness Inventory website and journal entries during each assignment (on the 12 dimensions of wellness) would have an effect on changes in wellness dimensions.

\section{METHODS}

PED101 students $(N=1,497)$ taking PED 101 were assessed at the beginning of the semester (January 2018) for each dimension of wellness and then again at the end of the semester (May 2018) for an assessment of wellness. The courses were online with resources available through the Wellness Inventory for dimensions of wellness and an eBook was also used through Tophat for students to work through tutorials online about health and wellness.

Demographics were recorded by student self-report for Sex (Male $=556$, Female $=927$, other $=0$, Total $=1,483)$ and Health Status $($ Excellent $=335$, Good $=873$, Fair $=271$ and Poor $=18$, Total $=1,497)$. Since the demographic questions were not required to be answered by the wellness inventory, there is an uneven number of demographic categories. Health status was a onetime self-report during the initial assessment, as students ranked themselves in categories of excellent, good, fair, or poor based on their perceptions of their current health.

Each class was a two-credit hybrid course that met the physical activity recommendations suggested by the National Guidelines for Physical Activity for American 2019 (Physical Activity Guidelines Advisory Committee) of 150 mins each week. The course consisted of two parts (1) a face-to-face laboratory and (2) an online lecture component. In the face-to-face laboratory, students signed up for different classes offered from a menu of approximately 40 classes including; martial arts classes, strength and condition classes, aerobic exercise classes and yoga. The face-to-face lab consisted of assignments and readings that were conducted through Tophat's (Nanney, 2019) online book. There was also an online lecture component that addressed educational activities on the specific 12 dimensions of wellness (Travis, 2004). Students accessed study center tutorials through the wellness inventory about different dimensions of wellness. Throughout the semester students created action steps to help guide them on a path towards wellness through a process of implementing small steps to continuous improvement (Cardinal et al., 2015).

This course consisted of participation in a physical activity component where students attended a face-to-face physical activity class. Along with the face-to-face class there were educational materials designed as assignments to increase awareness and development of the physical, spiritual, emotional, social, and intellectual components of wellness, becoming an informed health consumer, and the application of healthy lifestyle choices for improved quality 
of life. The PED 101 is a 2-credit class that is required of all university students and meets the University Studies Lifespan Wellness requirement.

\section{Measures}

The wellness inventory was used at the beginning and the end of the semester to assess overall student ratings on the 12 dimensions of wellness. The Wellness Inventory has been shown to be both reliable and valid in the assessment of overall college student population (Travis, 2004).

The 12 dimensions of wellness assessed by the wellness inventory include (Travis, 2004); Self-Responsibility and Love that entails expressing ideas and emotions, in ways that communicate with others effectively while remaining faithful to self. Breathing assesses how factors of breathing affect output or general metabolism and a person's ability to work, play and communicate. Sensing is comprised of developing skills and becoming aware of how to appreciate and use our sensory input efficiently and creatively. Eating deals with assessing and teaching students how food not only affects physical health, but how it plays a role on emotions. Moving addresses how movement of the body plays a role in holistic wellbeing, how movement affects both physical and emotional health. Factors of Feeling, this dimension is about becoming aware of our emotions and feelings and how they may have an affect us. The Thinking dimension focuses on how thinking can be effected by both emotional and physical health and how improved health can relate to improved thinking. Playing and Working focuses on recapturing the spirit of play and how this can bring balance to people's lives when they are overwhelmed from work and other responsibilities. Communicating focuses primarily on verbal communication, and how we talk to ourselves as well as how we speak with others, while also examining some of the potentials for breakdown in communication that may occur. The Intimacy dimension addresses how we connect with others and build relationships effectively. The Finding Meaning dimension helps assess how people find meaning in life and offers suggestions of activities to help them find some meaning and purpose in their life. Transcending is about finding that peak experience or flow state, it is an experience of being fully awake and engaged in the present moment. The wellness inventory is a 10-point Likerttype scale with no reverse scored items ranging from 0 (the lowest point) to 10 (the highest point).

\section{Statistical Analysis}

Scores for the 12 dimensions were collected from the Wellness Inventory database of all the classes. There were no identifying factors such as names or date of birth available, so confidentiality was maintained. To analyze the data, ANOVAs were conducted on the aggregated averages from the wellness inventory output for each class to assess overall differences in wellness inventory dimension changes. ANOVAs were used to compute differences in demographic variables. Repeated Measures ANOVAs were used to assess for changes in overall ratings for sex, and self-reported health status to see if changes occurred in ratings pre to post course. ANOVAs were also conducted to see if there were any differences in Wellness Inventory scores at the pre-assessment and post-assessment between demographic variables. ANOVA modeling was also utilized to see if resources and journals had effects on wellness inventory outcomes.

\section{RESULTS AND ANALYSIS}

Pre/post assessment of all the pre/post data showed significant increases in all 12 dimensions of wellness overall for preassessment to post-assessment (see Table 1). These results prove promising for the information provided during the class as we are seeing increases in all dimensions of wellness at the end of the semester. 
Table 1

Overall Pre/Post

\begin{tabular}{|c|c|c|c|c|c|c|c|}
\hline \multirow[t]{2}{*}{ Dimension $(\mathrm{N}=1497)$} & \multicolumn{2}{|l|}{ Pre } & \multicolumn{2}{|l|}{ Post } & \multirow[b]{2}{*}{$\mathbf{F}$} & \multirow[b]{2}{*}{$p$} & \multirow[b]{2}{*}{ d } \\
\hline & Mean & $\underline{\mathrm{SD}}$ & Mean & $\underline{\mathrm{SD}}$ & & & \\
\hline Self-Resp \& Love & $\overline{69.69}$ & $\overline{12.87}$ & $78.50^{* * *}$ & $\overline{13.21}$ & $\mathrm{~F}(1,2670)=304.80$ & $<.0001$ & .067 \\
\hline Breathing & 54.80 & 17.80 & $72.75^{* * *}$ & 16.47 & $F(1,2672)=732.28$ & $<.0001$ & 1.05 \\
\hline Sensing & 64.65 & 14.10 & $76.10^{* * *}$ & 14.26 & $\mathrm{~F}(1,2702)=440.35$ & $<.0001$ & 0.81 \\
\hline Eating & 64.62 & 14.18 & $76.09^{* * *}$ & 14.30 & $\mathrm{~F}(1,2700)=370.54$ & $<.0001$ & 0.74 \\
\hline Moving & 58.80 & 19.57 & $73.25^{* * *}$ & 17.34 & $\mathrm{~F}(1,2702)=416.53$ & $<.0001$ & 0.78 \\
\hline Feeling & 58.80 & 19354 & $73.25^{* * *}$ & 17.31 & $\mathrm{~F}(1,2706)=311.36$ & $<.0001$ & 0.68 \\
\hline Thinking & 61.81 & 16.45 & $73.77^{* * *}$ & 15.94 & $\mathrm{~F}(1,2708)=368.45$ & $<.0001$ & 0.73 \\
\hline Playing \& Working & 63.34 & 16.29 & $74.77^{* * *}$ & 16.05 & $\mathrm{~F}(1,2702)=338.05$ & $<.0001$ & 0.71 \\
\hline Communicating & 74.67 & 13.54 & $80.13^{* * *}$ & 13.82 & $\mathrm{~F}(1,2702)=107.66$ & $<.0001$ & 0.40 \\
\hline Intimacy & 75.37 & 15.55 & $81.89^{* * *}$ & 14.42 & $\mathrm{~F}(1,2706)=127.90$ & $<.0001$ & 0.43 \\
\hline Finding Meaning & 66.77 & 16.10 & $76.19^{* * *}$ & 15.78 & $\mathrm{~F}(1,2706)=236.44$ & $<.0001$ & 0.59 \\
\hline Transcending & 63.89 & 16.61 & $75.40^{* * *}$ & 16.19 & $\mathrm{~F}(1,2708)=333.71$ & $<.0001$ & 0.70 \\
\hline
\end{tabular}

$*<.01, * *<.001, * * *<.0001$

\section{Gender}

When looking at gender both males (see Table 2) and females (see Table 3) showed significant changes from preassessment to post-assessment, with large effect sizes for most of the measures as well for both males and females, except for the Moving dimension which showed a medium $(d=.069)$ effect size.

Table 2

Males Pre/Post

\begin{tabular}{|l|l|l|l|l|l|l|l|}
\hline \multirow{2}{*}{ Dimension (N 56) } & Pre & \multicolumn{2}{l}{ Post } & \multicolumn{2}{l}{} \\
\cline { 2 - 7 } & $\underline{\text { Mean }}$ & $\underline{\text { SD }}$ & $\underline{\text { Mean }}$ & $\underline{\text { SD }}$ & F & p & d \\
\hline Self-Resp \& Love & 69.17 & 2.38 & $74.94^{* * *}$ & 2.24 & $\mathrm{~F}(1,1110)=1732.90$ & $<.0001$ & 6.82 \\
\hline Breathing & 56.17 & 3.13 & $69.83^{* * *}$ & 2.38 & $\mathrm{~F}(1,1110)=6710.12$ & $<.0001$ & 4.91 \\
\hline Sensing & 64.94 & 4.71 & $73.89^{* * *}$ & 2.45 & $\mathrm{~F}(1,1110)=1580.08$ & $<.0001$ & 2.38 \\
\hline Eating & 53.06 & 4.33 & $65.89^{* * *}$ & 7.74 & $\mathrm{~F}(1,1110)=1163.57$ & $<.0001$ & 2.05 \\
\hline Moving & 60.83 & 4.06 & $70.61^{* * *}$ & 2.70 & $\mathrm{~F}(1,1110)=2236.96$ & $<.0001$ & 2.84 \\
\hline Feeling & 64.17 & 2.50 & $72.22^{* * *}$ & 2.44 & $\mathrm{~F}(1,1110)=2952.42$ & $<.0001$ & 3.26 \\
\hline Thinking & 64.00 & 2.25 & $71.67^{* * *}$ & 2.93 & $\mathrm{~F}(1,1110)=2396.71$ & $<.0001$ & 2.94 \\
\hline Playing \& Working & 66.17 & 2.36 & $73.00^{* * *}$ & 2.54 & $\mathrm{~F}(1,1110)=2157.59$ & $<.0001$ & 2.76 \\
\hline Communicating & 73.11 & 2.11 & $76.78^{* * *}$ & 2.13 & $\mathrm{~F}(1,1110)=833.10$ & $<.0001$ & 1.73 \\
\hline Intimacy & 73.72 & 2.72 & $78.28^{* * *}$ & 1.49 & $\mathrm{~F}(1,1110)=1201.98$ & $<.0001$ & 2.08 \\
\hline Finding Meaning & 67.67 & 2.72 & $74.00^{* * *}$ & 2.35 & $\mathrm{~F}(1,1110)=1724.21$ & $<.0001$ & 2.49 \\
\hline Transcending & 62.83 & 3.05 & $72.22^{* * *}$ & 2.73 & $\mathrm{~F}(1,1110)=2925.84$ & $<.0001$ & 3.24 \\
\hline
\end{tabular}

$*<.01, * *<.001, * * *<.0001$ 
Table 3

Females Pre/ Post

\begin{tabular}{|l|l|l|l|l|l|l|l|}
\hline \multirow{2}{*}{ Dimension (N =927) } & \multicolumn{2}{l}{ Pre } & \multicolumn{2}{l}{ Post } & \multicolumn{2}{l|}{} \\
\cline { 2 - 7 } & $\underline{\text { Mean }}$ & $\underline{\mathbf{S D}}$ & $\underline{\text { Mean }}$ & $\underline{\text { SD }}$ & F & p & d \\
\hline Self-Resp \& Love & 68.83 & 3.79 & $77.50^{* * *}$ & 1.82 & $\mathrm{~F}(1,1852)=3942.05$ & $<.0001$ & 2.92 \\
\hline Breathing & 54.00 & 1.97 & $70.83^{* * *}$ & 6.34 & $\mathrm{~F}(1,1852)=5957.18$ & $<.0001$ & 3.59 \\
\hline Sensing & 63.22 & 1.86 & $73.06^{* * *}$ & 2.01 & $\mathrm{~F}(1,1852)=11968.12$ & $<.0001$ & 5.08 \\
\hline Eating & 52.50 & 2.96 & $63.83^{* * *}$ & 3.76 & $\mathrm{~F}(1,1852)=5196.60$ & $<.0001$ & 3.35 \\
\hline Moving & 58.17 & 4.34 & $66.11^{* * *}$ & 15.50 & $\mathrm{~F}(1,1852)=225.57$ & $<.0001$ & 0.69 \\
\hline Feeling & 63.83 & 2.68 & $73.06^{* * *}$ & 2.04 & $\mathrm{~F}(1,1852)=6936.72$ & $<.0001$ & 3.88 \\
\hline Thinking & 60.28 & 1.93 & $70.78^{* * *}$ & 2.13 & $\mathrm{~F}(1,1852)=12370.40$ & $<.0001$ & 5.17 \\
\hline Playing \& Working & 62.33 & 2.22 & $72.61^{* * *}$ & 2.73 & $\mathrm{~F}(1,1852)=7312.24$ & $<.0001$ & 4.13 \\
\hline Communicating & 74.67 & 2.14 & $79.28^{* * *}$ & 1.93 & $\mathrm{~F}(1,1852)=2372.29$ & $<.0001$ & 2.26 \\
\hline Intimacy & 75.56 & 1.79 & $80.44^{* * *}$ & 2.53 & $\mathrm{~F}(1,1852)=2298.38$ & $<.0001$ & 2.23 \\
\hline Finding Meaning & 65.72 & 2.24 & $73.94^{* * *}$ & 2.94 & $\mathrm{~F}(1,1852)=4584.95$ & $<.0001$ & 3.14 \\
\hline Transcending & 63.78 & 1.90 & $73.61^{* * *}$ & 2.73 & $\mathrm{~F}(1,1852)=8096.88$ & $<.0001$ & 2.48 \\
\hline
\end{tabular}

$$
*<.01, * *<.001, * * *<.0001
$$

\section{Pre-Assessment Self-Reported Health Ratings Differences (see Table 4 for Means and Standard Deviations)}

Between analysis results on pre-assessment outcomes for all groups showed that students ability to accurately rate and selfreport their health status was consistent as supported by the pre-assessment outcomes between groups of self reported health status. Students rating themselves as being in excellent health also reported significantly higher ratings on the twelve dimensions that students in fair, good and poor health. These results for most of the scales do show a trend from excellent to poor ratings with excellent health status students reporting higher scores in all 12 dimensions than poor health status students.

ANOVAs showed students identifying as being in Excellent health reported significantly higher ratings for; Self Responsibility $\mathrm{F}(3,1493)=781.72, p<.0001$, Breathing $\mathrm{F}(3,1493)=320.16, p<.0001$, Sensing $\mathrm{F}(3,1493)=954.00, p<$ .0001 , Eating $\mathrm{F}(3,1493)=229.05, p<.0001$, Moving $\mathrm{F}(3,1493)=295.68, p<.0001$, Feeling $\mathrm{F}(3,1493)=1411.33, p<.0001$, Thinking $\mathrm{F}(3,1493)=260.47, p<.0001$, Playing \& Working $\mathrm{F}(3,1493)=973.42, p<.0001$, Communicating $\mathrm{F}(3,1493)=$ 1939.29, $p<.0001$, Intimacy F(3, 1493) $=452.19, p<.0001$, Finding Meaning $\mathrm{F}(3,1493)=175.45, p<.0001$ and Transcending $\mathrm{F}(3,1493)=393.01, p<.0001$ than students in Good Health.

ANOVAs showed students identifying as being in Excellent health reported significantly higher ratings for Self Responsibility $\mathrm{F}(3,1493)=781.72, p<.0001$, Breathing $\mathrm{F}(3,1493)=320.16, p<.0001$, Sensing $\mathrm{F}(3,1493)=954.00, p<$ .0001 , Moving $\mathrm{F}(3,1493)=2952.68, p<.0001$, Feeling $\mathrm{F}(3,1493)=1411.32, p<.0001$, Thinking $\mathrm{F}(3,1493)=260.47, p<$ .0001 , Playing \& Working $\mathrm{F}(3,1493)=973.42, p<.0001$, Communicating $\mathrm{F}(3,1493)=1939.29, p<.0001$, Intimacy $\mathrm{F}(3$, $1493)=452.19, p<.0001$, Finding Meaning F(3,1493) $=175.45, p<.0001$ and Transcending F $(3,1493)=393.01, p<.0001$ than students in Fair Health. Students in Excellent health did not report significantly higher ratings for Eating than students that reporting being in Fair health.

ANOVAs showed students identifying as being in Excellent health reported significantly higher ratings for; Self Responsibility $\mathrm{F}(3,1493)=781.72, p<.0001$, Breathing $\mathrm{F}(3,1493)=320.16, p<.0001$, Sensing $\mathrm{F}(3,1493)=954.00, p<$ .0001 , Eating $\mathrm{F}(3,1493)=229.05, p<.0001$, Moving $\mathrm{F}(3,1493)=295.68, p<.0001$, Feeling $\mathrm{F}(3,1493)=1411.33, p<.0001$, 
Thinking $\mathrm{F}(3,1493)=260.47, p<.0001$, Playing \& Working $\mathrm{F}(3,1493)=973.42, p<.0001$, Communicating $\mathrm{F}(3,1493)=$ 1939.29, $p<.0001$, Intimacy $\mathrm{F}(3,1493)=452.19, p<.0001$, Finding Meaning $\mathrm{F}(3,1493)=175.45, p<.0001$ and Transcending $\mathrm{F}(3,1493)=393.01, p<.0001$ than students in Poor Health.

ANOVAs showed students identifying as being in Good health reported significantly higher ratings for; Self Responsibility $\mathrm{F}(3,1493)=781.72, p<.0001$, Breathing $\mathrm{F}(3,1493)=320.16, p<.0001$, Sensing $\mathrm{F}(3,1493)=954.00, p<$ .0001 , Eating $\mathrm{F}(3,1493)=229.05, p<.0001$, Moving $\mathrm{F}(3,1493)=295.68, p<.0001$, Feeling $\mathrm{F}(3,1493)=1411.33, p<.0001$, Thinking F(3, 1493) $=260.47, p<.0001$, Playing \& Working F(3, 1493) $=973.42, p<.0001$, Communicating $\mathrm{F}(3,1493)=$ 1939.29, $p<.0001$, Intimacy $\mathrm{F}(3,1493)=452.19, p<.0001$, Finding Meaning $\mathrm{F}(3,1493)=175.45, p<.0001$ and Transcending $\mathrm{F}(3,1493)=393.01, p<.0001$ than students in Fair Health.

ANOVAs showed students identifying as being in Good health reported significantly higher ratings for; Self Responsibility $\mathrm{F}(3,1493)=781.72, p<.0001$, Breathing $\mathrm{F}(3,1493)=320.16, p<.0001$, Sensing $\mathrm{F}(3,1493)=954.00, p<$ .0001 , Eating $\mathrm{F}(3,1493)=229.05, p<.0001$, Moving $\mathrm{F}(3,1493)=295.68, p<.0001$, Feeling $\mathrm{F}(3,1493)=1411.33, p<.0001$, Thinking $\mathrm{F}(3,1493)=260.47, p<.0001$, Playing \& Working $\mathrm{F}(3,1493)=973.42, p<.0001$, Communicating $\mathrm{F}(3,1493)=$ 1939.29, $p<.0069$, Intimacy $\mathrm{F}(3,1493)=452.19, p<.0001$, Finding Meaning $\mathrm{F}(3,1493)=175.45, p<.0001$ and Transcending $\mathrm{F}(3,1493)=393.01, p<.0001$ than students in Poor Health.

ANOVAs showed students identifying as being in Fair health reported significantly higher ratings for; Self Responsibility $\mathrm{F}(3,1493)=781.72, p<.0001$, Breathing $\mathrm{F}(3,1493)=320.16, p<.0001$, Sensing $\mathrm{F}(3,1493)=954.00, p<.0001, \mathrm{Eating} \mathrm{F}(3$, $1493)=229.05, p<.0001$, Moving $\mathrm{F}(3,1493)=295.68, p<.0001$, Feeling $\mathrm{F}(3,1493)=1411.33, p<.0001$, Thinking $\mathrm{F}(3$, $1493)=260.47, p<.02$, Playing \& Working $\mathrm{F}(3,1493)=973.42, p<.0001$, Communicating $\mathrm{F}(3,1493)=1939.29, p<.0001$, Finding Meaning $\mathrm{F}(3,1493)=175.45, p<.0001$ and Transcending $\mathrm{F}(3,1493)=393.01, p<.002$ than students in Poor Health. Students in Fair health did not show significant differences at pre-assessment on Intimacy than students in Poor health.

Table 4

Health Status Scores Pre-Assessment

\begin{tabular}{|c|c|c|c|c|c|c|c|c|}
\hline \multirow[t]{2}{*}{$\begin{array}{l}\text { Dimension } \\
\text { (Pre-assessment) }\end{array}$} & \multicolumn{2}{|c|}{$\begin{array}{l}\text { Excellent } \\
(\mathrm{N}=335)\end{array}$} & \multicolumn{2}{|c|}{$\begin{array}{l}\text { Good } \\
(N=873)\end{array}$} & \multicolumn{2}{|c|}{$\begin{array}{l}\text { Fair } \\
(\mathbf{N}=271)\end{array}$} & \multicolumn{2}{|c|}{$\begin{array}{l}\text { Poor } \\
(N=18)\end{array}$} \\
\hline & Mean & $\underline{\mathrm{SD}}$ & $\underline{\text { Mean }}$ & $\underline{\mathrm{SD}}$ & Mean & $\underline{\mathrm{SD}}$ & $\underline{\text { Mean }}$ & $\underline{\mathrm{SD}}$ \\
\hline Self-Resp \& Love & 73.56 & 2.87 & 69.39 & 2.06 & 65.00 & 1.41 & 60.18 & 8.41 \\
\hline Breathing & 59.44 & 4.72 & 54.89 & 2.40 & 62.56 & 6.82 & 44.73 & 9.30 \\
\hline Sensing & 67.39 & 4.30 & 63.94 & 2.29 & 50.39 & 6.87 & 57.91 & 12.09 \\
\hline Eating & 58.94 & 3.95 & 53.22 & 2.62 & 58.17 & 6.71 & 43.82 & 16.27 \\
\hline Moving & 68.56 & 3.91 & 60.44 & 2.85 & 42.78 & 4.36 & 36.82 & 9.03 \\
\hline Feeling & 68.44 & 4.13 & 64.28 & 2.30 & 47.50 & 6.71 & 55.91 & 16.01 \\
\hline Thinking & 66.78 & 4.19 & 61.28 & 2.54 & 57.89 & 6.26 & 54.91 & 14.19 \\
\hline Playing \& Working & 69.11 & 2.47 & 63.78 & 1.90 & 56.17 & 4.48 & 49.73 & 15.35 \\
\hline Communicating & 77.56 & 3.20 & 74.00 & 1.50 & 57.78 & 6.02 & 71.36 & 11.98 \\
\hline Intimacy & 78.00 & 1.68 & 75.22 & 1.52 & 69.78 & 3.77 & 70.73 & 17.14 \\
\hline Finding Meaning & 71.11 & 2.81 & 66.61 & 2.12 & 69.39 & 5.65 & 60.45 & 13.69 \\
\hline Transcending & 67.67 & 3.83 & 67.67 & 3.83 & 58.89 & 4.42 & 56.00 & 13.13 \\
\hline
\end{tabular}

$*<.01, * *<.001, * * *<.0001$ 


\section{Post-Assessment Health Rating Differences (see Table 5 for Means and Standard Deviations)}

Consistent with the pre-assessment between differences outcomes there are consistent trends that excellent selfreported health status students had higher ratings on all twelve dimensions than did students of good, fair and poor health status. With a trend of higher ratings existing for most (but not all) dimensions with improved health status. Although we are still seeing difference in health status with excellent health status students reporting higher rating, the good news about these outcomes that all groups are showing improvements. These results show us that no matter where someone is on the health continuum getting pointed towards the direction of wellness is possible.

ANOVAs showed that students that identified as being in Excellent health reported significantly higher ratings for; Self Responsibility F(3, 1493) $=238.17, p<.0001$, Breathing $\mathrm{F}(3,1493)=25.53, p<.0001$, Sensing $\mathrm{F}(3,1493)=$ 464.37, $p<.0001$, Eating $\mathrm{F}(3,1493)=135.73, p<.0001$, Moving $\mathrm{F}(3,1493)=1167.39, p<.0001, \mathrm{Feeling} \mathrm{F}(3,1493)$ $=661.23, p<.0001$, Thinking $\mathrm{F}(3,1493)=164.22, p<.0001$, Playing \& Working $\mathrm{F}(3,1493)=417.88, p<.0001$, Communicating $\mathrm{F}(3,1493)=728.96, p<.0001$, Intimacy $\mathrm{F}(3,1493)=282.85, p<.0001$, Finding Meaning $\mathrm{F}(3,1493)$ $=85.95, p<.0001$ and Transcending $\mathrm{F}(3,1493)=260.96, p<.0001$ than students in Good Health.

ANOVAs showed that students that identified as being in Excellent health reported significantly higher ratings for; Self Responsibility F(3, 1493) $=238.17, p<.0001$, Sensing F(3, 1493) $=464.37, p<.0001$, Eating F(3, 1493) $=$ 135.73, $p<.0001$, Moving $\mathrm{F}(3,1493)=1167.39, p<.0001$, Feeling $\mathrm{F}(3,1493)=661.23, p<.0001$, Thinking $\mathrm{F}(3$, $1493)=164.22, p<.0001$, Playing \& Working $\mathrm{F}(3,1493)=417.88, p<.0001$, Communicating $\mathrm{F}(3,1493)=728.96$, $p<.0001$, Intimacy $\mathrm{F}(3,1493)=282.85, p<.0001$, Finding Meaning $\mathrm{F}(3,1493)=85.95, p<.0001$ and Transcending $\mathrm{F}(3,1493)=260.96, p<.0001$ than students in Fair Health. Students in Excellent health did not show significant differences at post-assessment on Breathing and Eating than students in Fair health.

ANOVAs at post-assessment showed that students that identified as being in Excellent health reported significantly higher ratings for all 12 dimensions over students that rated themselves as being in Poor health; Self Responsibility $\mathrm{F}(3,1493)=238.17, p<.0001$, Breathing $\mathrm{F}(3,1493)=25.53, p<.0001$, Sensing $\mathrm{F}(3,1493)=464.37$, $p<.0001$, Eating $\mathrm{F}(3,1493)=135.73, p<.0001$, Moving $\mathrm{F}(3,1493)=1167.39, p<.0001$, Feeling $\mathrm{F}(3,1493)=$ 661.23, $p<.0001$, Thinking $\mathrm{F}(3,1493)=164.22, p<.0001$, Playing \& Working $\mathrm{F}(3,1493)=417.88, p<.0001$, Communicating $\mathrm{F}(3,1493)=728.96, p<.0001$, Intimacy $\mathrm{F}(3,1493)=282.85, p<.0001$, Finding Meaning $\mathrm{F}(3,1493)$ $=85.95, p<.0001$ and Transcending $\mathrm{F}(3,1493)=260.96, p<.0001$.

ANOVAs showed students identifying as being in Good health reported significantly higher ratings for; Self Responsibility $\mathrm{F}(3,1493)=781.72, p<.0001$, Breathing $\mathrm{F}(3,1493)=320.16, p<.0001$, Sensing $\mathrm{F}(3,1493)=954.00$, $p<.0001$, Eating F(3, 1493) $=229.05, p<.0001$, Moving F $(3,1493)=295.68, p<.0001$, Feeling $\mathrm{F}(3,1493)=1411.33$, $p<.0001$, Thinking $\mathrm{F}(3,1493)=260.47, p<.0001$, Playing \& Working $\mathrm{F}(3,1493)=973.42, p<.0001$, Communicating $\mathrm{F}(3,1493)=1939.29, p<.0001$, Intimacy $\mathrm{F}(3,1493)=452.19, p<.0001$, and Transcending $\mathrm{F}(3$, $1493)=393.01, p<.0001$ than students in Fair Health. Finding Meaning was not rated as significantly different between Good and Fair health rated students.

ANOVAs showed students identifying as being in Good health reported significantly higher ratings for all 12 dimensions; Self Responsibility F(3, 1493) $=781.72, p<.0001$, Breathing F(3, 1493) = 320.16, $p<.0001$, Sensing F(3, $1493)=954.00, p<.0001$, Eating $\mathrm{F}(3,1493)=229.05, p<.0001$, Moving $\mathrm{F}(3,1493)=295.68, p<.0001$, Feeling $\mathrm{F}(3,1493)=1411.33, p<.0001$, Thinking $\mathrm{F}(3,1493)=260.47, p<.0001$, Playing \& Working $\mathrm{F}(3,1493)=973.42, p$ $<.0001$, Communicating $\mathrm{F}(3,1493)=1939.29, p<.0001$, Intimacy $\mathrm{F}(3,1493)=452.19, p<.0001$, Finding Meaning 
$\mathrm{F}(3,1493)=175.45, p<.0001$ and Transcending $\mathrm{F}(3,1493)=393.01, p<.0001$ over students that reported being in Poor Health.

ANOVAs showed students identifying as being in Fair health reported significantly higher ratings for; Self Responsibility $\mathrm{F}(3,1493)=781.72, p<.0001$, Breathing $\mathrm{F}(3,1493)=320.16, p<.0001$, Sensing $\mathrm{F}(3,1493)=954.00$, $p<.02$, Eating $\mathrm{F}(3,1493)=229.05, p<.0001$, Thinking $\mathrm{F}(3,1493)=260.47, p<.02$, Communicating $\mathrm{F}(3,1493)=$ $1939.29, p<.004$, Intimacy F $(3,1493)=452.19, p<.0001$, and Finding Meaning F $(3,1493)=175.45, p<.0001$ than students in Poor Health. Students in Fair health did not show significant differences at pre-assessment on Intimacy than students in Poor health. There was no significant difference for Moving, Feeling, Playing \& Working, Transcending between Fair and Poor health rated students.

Table 5

Health Status Scores Post-Assessment

\begin{tabular}{|c|c|c|c|c|c|c|c|c|}
\hline \multirow[t]{2}{*}{$\begin{array}{l}\text { Dimension } \\
\text { (Pre-assessment) }\end{array}$} & \multicolumn{2}{|c|}{$\begin{array}{l}\text { Excellent } \\
(\mathbf{N}=335)\end{array}$} & \multicolumn{2}{|c|}{$\begin{array}{l}\text { Good } \\
(\mathbf{N}=873)\end{array}$} & \multicolumn{2}{|c|}{$\begin{array}{l}\text { Fair } \\
(N=271)\end{array}$} & \multicolumn{2}{|c|}{$\begin{array}{l}\text { Poor } \\
(N=18)\end{array}$} \\
\hline & Mean & $\underline{\mathrm{SD}}$ & Mean & Mean & $\underline{\mathrm{SD}}$ & $\underline{\mathrm{SD}}$ & Mean & $\underline{\mathrm{SD}}$ \\
\hline Self-Resp \& Love & $78.94^{* * *}$ & 4.68 & $76.72^{* * *}$ & 2.16 & $72.50^{* * *}$ & 0.71 & $69.00^{*}$ & 15.05 \\
\hline Breathing & $71.94^{* * *}$ & 5.70 & $70.33^{* * *}$ & 2.61 & $71.78^{* * *}$ & 5.05 & $64.73^{*}$ & 19.33 \\
\hline Sensing & $76.00^{* * *}$ & 4.45 & $73.94^{* * *}$ & 2.29 & $64.33^{* * *}$ & 5.78 & 67.27 & 18.84 \\
\hline Eating & $68.39^{* * *}$ & 6.62 & $63.83^{* * *}$ & 2.23 & $68.22^{* * *}$ & 7.14 & 53.27 & 14.69 \\
\hline Moving & $76.56^{* * *}$ & 5.19 & $70.72^{* * *}$ & 3.12 & $55.72^{* * *}$ & 5.94 & $54.73^{* * *}$ & 15.68 \\
\hline Feeling & $76.39^{* * *}$ & 3.55 & $73.11^{* * *}$ & 2.59 & $61.39^{* * *}$ & 6.90 & 63.18 & 19.69 \\
\hline Thinking & $74.44^{* * *}$ & 4.18 & $71.67^{* * *}$ & 2.52 & $67.83^{* * *}$ & 5.95 & 60.73 & 17.66 \\
\hline Playing \& Working & $77.11^{* * *}$ & 3.71 & $72.78^{* * *}$ & 2.69 & $66.33^{* * *}$ & 4.47 & $66.82^{* *}$ & 17.55 \\
\hline Communicating & $80.83^{* * *}$ & 3.47 & $78.44^{* * *}$ & 2.31 & $67.44^{* * *}$ & 5.59 & 70.64 & 16.93 \\
\hline Intimacy & $82.89^{* * *}$ & 2.76 & $80.28^{* * *}$ & 2.54 & $75.17^{* * *}$ & 3.81 & 71.00 & 19.65 \\
\hline Finding Meaning & $77.72^{* * *}$ & 3.34 & $74.56^{* * *}$ & 2.96 & $74.72^{* * *}$ & 5.20 & 65.18 & 19.62 \\
\hline Transcending & $77.06^{* * *}$ & 4.14 & $77.06^{* * *}$ & 4.14 & $67.44^{* * *}$ & 6.08 & $67.27^{*}$ & 15.25 \\
\hline
\end{tabular}

$*<.01, * *<.001, * * *<.0001$

\section{Health Status Pre/Post}

Excellent. For pre/post assessment of students that reported being in excellent health (see Table 6) status Repeated Measures ANOVAs showed significant increases in all 12 dimensions from pre- to post-assessment. All scores but Breathing $(d=.0001)$ showed a large effect size for individuals self-reporting as being in Excellent health status.

Good. For pre/post assessment of students that reported being in Good health status (see Table 7) results showed significant increases in all 12 dimensions from pre- to post-assessment. All 12 dimensions showed larger effect sizes as well. 
Table 6

Excellent Health Status Wellness Scores Pre/Post

\begin{tabular}{|l|l|l|l|l|l|l|l|}
\hline \multirow{2}{*}{$\begin{array}{l}\text { Dimension } \\
(\mathbf{N}=335)\end{array}$} & Pre & \multicolumn{2}{l}{ Post } & \multicolumn{2}{l|}{} \\
\cline { 2 - 7 } Self-Resp \& Love & $\underline{\text { Mean }}$ & $\underline{\text { SD }}$ & $\underline{\text { Mean }}$ & $\underline{\text { SD }}$ & F & p & d \\
\hline Breathing & 73.56 & 2.87 & $78.94^{* * *}$ & 4.68 & $\mathrm{~F}(1,668)=621.72$ & $<.0001$ & 1.39 \\
\hline Sensing & 59.44 & 4.72 & $71.94^{* * *}$ & 5.70 & $\mathrm{~F}(1,668)=955.73$ & $<.0001$ & .0001 \\
\hline Eating & 67.39 & 4.30 & $76.00^{* * *}$ & 4.45 & $\mathrm{~F}(1,668)=648.54$ & $<.0001$ & 1.97 \\
\hline Moving & 58.94 & 3.95 & $68.39^{* * *}$ & 6.62 & $\mathrm{~F}(1,668)=503.41$ & $<.0001$ & 1.73 \\
\hline Feeling & 68.56 & 3.91 & $76.56^{* * *}$ & 5.19 & $\mathrm{~F}(1,668)=507.77$ & $<.0001$ & 1.74 \\
\hline Thinking & 68.44 & 4.13 & $76.39^{* * *}$ & 3.55 & $\mathrm{~F}(1,668)=713.87$ & $<.0001$ & 2.06 \\
\hline Playing \& Working & 66.78 & 4.19 & $74.44^{* * *}$ & 4.18 & $\mathrm{~F}(1,668)=561.15$ & $<.0001$ & 1.83 \\
\hline Communicating & 69.11 & 2.47 & $77.11^{* * *}$ & 3.71 & $\mathrm{~F}(1,668)=1079.29$ & $<.0001$ & 2.54 \\
\hline Intimacy & 77.56 & 3.20 & $80.83^{* * *}$ & 3.47 & $\mathrm{~F}(1,668)=160.77$ & $<.0001$ & 0.98 \\
\hline Finding Meaning & 78.00 & 1.68 & $82.89^{* * *}$ & 2.76 & $\mathrm{~F}(1,668)=804.98$ & $<.0001$ & 2.19 \\
\hline Transcending & 71.11 & 2.81 & $77.72^{* * *}$ & 3.34 & $\mathrm{~F}(1,668)=1047.14$ & $<.0001$ & 2.14 \\
\hline
\end{tabular}

$*<.01, * *<.001, * * *<.0001$

Table 7

Good Health Status Wellness Scores Pre/Post

\begin{tabular}{|c|c|c|c|c|c|c|c|}
\hline \multirow{2}{*}{$\begin{array}{l}\text { Dimension } \\
(\mathrm{N}=873)\end{array}$} & \multicolumn{2}{|l|}{ Pre } & \multicolumn{2}{|l|}{ Post } & \multirow[b]{2}{*}{$\mathbf{F}$} & \multirow[b]{2}{*}{$\mathrm{p}$} & \multirow[b]{2}{*}{ d } \\
\hline & Mean & $\underline{\text { SD }}$ & Mean & $\underline{\mathrm{SD}}$ & & & \\
\hline Self-Resp \& Love & 69.39 & 2.06 & $76.72^{* * *}$ & 2.16 & $\mathrm{~F}(1,1744)=5264.82$ & $<.0001$ & 3.47 \\
\hline Breathing & 54.89 & 2.40 & $70.33^{* * *}$ & 2.61 & $\mathrm{~F}(1,1744)=16553.93$ & $<.0001$ & 6.16 \\
\hline Sensing & 63.94 & 2.29 & $73.94^{* * *}$ & 2.29 & $\mathrm{~F}(1,1744)=8544.58$ & $<.0001$ & 4.37 \\
\hline Eating & 53.22 & 2.62 & $63.83^{* * *}$ & 2.23 & $\mathrm{~F}(1,1744)=8302.18$ & $<.0001$ & 4.36 \\
\hline Moving & 60.44 & 2.85 & $70.72^{* * *}$ & 3.12 & $\mathrm{~F}(1,1744)=5166.48$ & $<.0001$ & 3.44 \\
\hline Feeling & 64.28 & 2.30 & $73.11^{* * *}$ & 2.59 & $\mathrm{~F}(1,1744)=8673.14$ & $<.0001$ & 3.61 \\
\hline Thinking & 61.28 & 2.54 & $71.67^{* * *}$ & 2.52 & $\mathrm{~F}(1,1744)=7361.52$ & $<.0001$ & 4.11 \\
\hline Playing \& Working & 63.78 & 1.90 & $72.78^{* * *}$ & 2.69 & $\mathrm{~F}(1,1744)=6519.67$ & $<.0001$ & 3.87 \\
\hline Communicating & 74.00 & 1.50 & $78.44^{* * *}$ & 2.31 & $\mathrm{~F}(1,1744)=2268.62$ & $<.0001$ & 2.28 \\
\hline Intimacy & 75.22 & 1.52 & $80.28^{* * *}$ & 2.54 & $\mathrm{~F}(1,1744)=2551.01$ & $<.0001$ & 2.42 \\
\hline Finding Meaning & 66.61 & 2.12 & $74.56^{* * *}$ & 2.96 & $\mathrm{~F}(1,1744)=4162.33$ & $<.0001$ & 3.09 \\
\hline Transcending & 67.67 & 3.83 & $77.06^{* * *}$ & 4.14 & $\mathrm{~F}(1,1744)=6493.95$ & $<.0001$ & 3.86 \\
\hline
\end{tabular}

$$
*<.01, * *<.001, * * *<.0001
$$

Fair. For pre/post assessment of students that reported being in fair health status (see Table 8) results showed significant increases in all 12 dimensions from pre- to post-assessment.

Poor. For pre/post assessment of students that reported being in poor health status (see Table 9) results showed significant increases in five of the 12 dimensions from pre- to post-assessment; Self-Responsibility $\mathrm{F}(1,34)=4.78, p$ $<0.36, d=0.72$, Breathing $\mathrm{F}(1,34)=15.65, p<.0004, d=1.32$, Moving $\mathrm{F}(1,34)=17.62, p<.0002, d=1.4$, Playing and Working $\mathrm{F}(1,34)=9.67, p<.004, d=1.04$, Transcending $\mathrm{F}(1,34)=5.65, p<.02, d=0.08$. There were no significant changes from pre- to post-assessment for; Sensing, Eating, Feeling, Thinking, Communicating, Intimacy and Finding Meaning for poor health status students. 
While all twelve dimensions for excellent, good and fair health status students showed significant increases from start to finish, poor health status students showed some increases from pre- to post-assessment. While not all scales for poor health had a significant increase in scores there was a trend for all twelve dimensions to show increases. The lack of significant for poor health status students may also be the result of such a small sample.

Table 8

Fair Health Status Wellness Scores Pre/ Post

\begin{tabular}{|c|c|c|c|c|c|c|c|}
\hline \multirow{2}{*}{$\begin{array}{l}\text { Dimension } \\
(\mathrm{N}=271)\end{array}$} & \multicolumn{2}{|l|}{ Pre } & \multicolumn{2}{|l|}{ Post } & \multirow[b]{2}{*}{$\mathbf{F}$} & \multirow[b]{2}{*}{$p$} & \multirow[b]{2}{*}{ d } \\
\hline & Mean & $\underline{\mathrm{SD}}$ & Mean & $\underline{\mathrm{SD}}$ & & & \\
\hline Self-Resp \& Love & $\overline{65.00}$ & $\overline{1.41}$ & $72.50^{* * *}$ & $\overline{0.71}$ & $\mathrm{~F}(1,540)=6116.58$ & $<.0001$ & 6.72 \\
\hline Breathing & 62.56 & 6.82 & $71.78^{* * *}$ & 5.05 & $\mathrm{~F}(1,540)=319.9$ & $<.0001$ & 1.54 \\
\hline Sensing & 50.39 & 6.87 & $64.33^{* * *}$ & 5.78 & $\mathrm{~F}(1,540)=653.33$ & $<.0001$ & 2.2 \\
\hline Eating & 58.17 & 6.71 & $68.22^{* * *}$ & 7.14 & $\mathrm{~F}(1,540)=285.11$ & $<.0001$ & 1.45 \\
\hline Moving & 42.78 & 4.36 & $55.72^{* * *}$ & 5.94 & $\mathrm{~F}(1,540)=835.78$ & $<.0001$ & 2.48 \\
\hline Feeling & 47.50 & 6.71 & $61.39^{* * *}$ & 6.90 & $\mathrm{~F}(1,540)=564.42$ & $<.0001$ & 2.04 \\
\hline Thinking & 57.89 & 6.26 & $67.83^{* * *}$ & 5.95 & $\mathrm{~F}(1,540)=358.97$ & $<.0001$ & 1.62 \\
\hline Playing \& Working & 56.17 & 4.48 & $66.33^{* * *}$ & 4.47 & $\mathrm{~F}(1,540)=698.46$ & $<.0001$ & 2.27 \\
\hline Communicating & 57.78 & 6.02 & $67.44^{* * *}$ & 5.59 & $\mathrm{~F}(1,540)=374.71$ & $<.0001$ & 1.66 \\
\hline Intimacy & 69.78 & 3.77 & $75.17^{* * *}$ & 3.81 & $\mathrm{~F}(1,540)=274.05$ & $<.0001$ & 1.42 \\
\hline Finding Meaning & 69.39 & 5.65 & $74.72^{* * *}$ & 5.20 & $\mathrm{~F}(1,540)=130.57$ & $<.0001$ & 0.98 \\
\hline Transcending & 58.89 & 4.42 & $67.44^{* * *}$ & 6.08 & $\mathrm{~F}(1,540)=350.62$ & $<.0001$ & 1.61 \\
\hline
\end{tabular}

$*<.01, * *<.001, * * *<.0001$

Table 9

Poor Health Status Wellness Scores Pre/Post

\begin{tabular}{|l|l|l|l|l|}
\hline \multirow{2}{*}{ Dimension } & \multicolumn{3}{l|}{$\begin{array}{l}\text { Poor-PRE } \\
(\mathbf{N}=\mathbf{1 8})\end{array}$} & \multicolumn{2}{l|}{$\begin{array}{l}\text { Poor-Post } \\
(\mathbf{N}=18)\end{array}$} \\
\cline { 2 - 5 } & $\underline{\text { Mean }}$ & $\underline{\underline{\text { SD }}}$ & $\underline{\text { Mean }}$ & $\underline{\underline{\text { SD }}}$ \\
\hline Self-Resp \& Love & 60.18 & 8.41 & $69.00^{*}$ & 15.05 \\
\hline Breathing & 44.73 & 9.30 & $64.73^{*}$ & 19.33 \\
\hline Sensing & 57.91 & 12.09 & 67.27 & 18.84 \\
\hline Eating & 43.82 & 16.27 & 53.27 & 14.69 \\
\hline Moving & 36.82 & 9.03 & $54.73^{* * *}$ & 15.68 \\
\hline Feeling & 55.91 & 16.01 & 63.18 & 19.69 \\
\hline Thinking & 54.91 & 14.19 & 60.73 & 17.66 \\
\hline Playing \& Working & 49.73 & 15.35 & $66.82^{* *}$ & 17.55 \\
\hline Communicating & 71.36 & 11.98 & 70.64 & 16.93 \\
\hline Intimacy & 70.73 & 17.14 & 71.00 & 19.65 \\
\hline Finding Meaning & 60.45 & 13.69 & 65.18 & 19.62 \\
\hline Transcending & 56.00 & 13.13 & $67.27^{*}$ & 15.25 \\
\hline
\end{tabular}

$*<.01, * *<.001, * * *<.0001$ 


\section{Journal Entries and Study Center Use}

Three models were conducted to test if the difference in the mean test scores were significantly impacted by study center use or journal count. Study center use was not a significant predictor for mean test score difference. Journal count tested as a significant predictor for mean test score difference; $\mathrm{F}(1,16202)=13.14, p<.03, \mathrm{R}^{2}=.0008$. An interaction between study center use and journal count was introduced, and journal count alone tested as a significant predictor of mean test score differences $\mathrm{F}(3,16200)=5.43, p<.0001$.

\section{DISCUSSION}

The implications for using the wellness inventory as an assessment tool in college student are promising. The results of this study offer evidence that a course design of teaching students about the 12 dimensions of wellness also shows promise for moving students in the direction of wellness as evidenced by the changes seen from pre-assessment to post-assessment on the wellness inventory. These results showed that overall college students showed significant increases in all 12 dimensions of wellness from the start of the semester to the end of the semester. Both males and females also showed significant increases in ratings of wellness from the start of the semester to the end of the semester and students that self-reported being in Excellent, Good, and Fair health reported significant changes in all 12 dimensions of wellness from the start of the semester to the end of the semester. While Poor health students did not report significant changes in all 12 dimensions of wellness, all dimensions but one (Communicating) did show improvements from start to finish. These outcomes may be the result of a small sample $(n=18)$ for poor health students compared to the other groups.

While this study was exploratory in nature, the outcomes do show promise that a PED101 course can be designed to help move students in the direction of wellness (DHHS, 2019; Cardinal, 2014). As previous researchers (DHHS, 2019; Cardinal, 2014) have argued for a more holistic approach to teaching as well as assessing wellbeing in college students, this study does just that. The pre/post outcomes from this study do show evidence that teaching students about wellness can change wellness scores over the course of a semester. In this study different demographic variables were examined to see if there were differences in gender or in students self-reported health status, from excellent to poor, and their ratings of wellness from the beginning of the semester (pre-assessment) to the end of the semester (post assessment).

When sex differences were examined at pre-assessment, males had significantly higher ratings than females for wellness dimensions on breathing, sensing, eating, moving, feeling, thinking, play and work, finding meaning, and females showed significantly higher ratings on; communicating, intimacy and transcending. At pre-assessment there were no differences in scores for self-responsibility and love between males and females. At post assessment males had significantly higher ratings on sensing, eating, moving, thinking, play and work, where females reported significantly higher ratings on; self-responsibility and love, breathing, feeling, communicating, intimacy and transcending. There were no significant differences in scores for gender on Finding Meaning at post-assessment. These outcomes show that there may be different points of focus on males and females while they are learning about and going through the wellness inventory educational tools and tutorials. Being aware of how wellness may look differently for the genders can help shape the way that the different dimensions are taught or to help frame the

dimensions to work to include relevant information for both sexes. Even with the between differences for males and 
females on the pre- and post-assessment of the wellness inventory, both groups had significant increases in all 12 dimensions from pre- to post-assessment.

These results indicate while males and females may experience wellness in different ways, the educational materials used on all 12 of wellness facilitated both toward a direction of wellness and away from the direction of illness. As Cardinal et al. (2015) and Errisuriz, Golaszewski, Born, and Bartholomew (2009) have recommended in their writing, this study has assessed student wellness and education beyond that of just health outcomes (e.g., exercise and weight). The results from this study have confirmed the previously stated hypothesis that overall wellness scores would increase from the start of the semester to the end of the semester.

These results also confirmed the hypothesis that males and females would both show significant increases in wellness scores and students that rated themselves as being in excellent or good health status would have higher wellness scores than students that rated themselves as being in fair or poor health status. The results also showed that most scores of wellness for the students rated in different health status did improve from start of the semester to end of the semester assessments on the wellness inventory. This study took Lothes and Nanney's (2019) research a step further by examining pre- and post- assessments of the Wellness Inventory (Travis, 2004), whereas they only examined between differences of demographic variables at the end of the semester using the Wellness Inventory.

These results show that students involved in physical education course that takes a holistic approach to wellbeing does help to improve multiple dimensions of wellbeing in different demographics of students from males to females as well as those that rate themselves from being in excellent to fair condition, with some significant increases in scores for individuals in poor health. However, the data does trend for increases in wellbeing scores, even if they do not reach a level of significance. This may also be the results of the poor health rated students being such a low number compared to the other groups. Future studies should examine more effective ways to specifically target poor health students to motivate and move them towards wellness.

Another interesting result is that even students rating themselves as being in excellent or fair health showed improvements in all 12 dimensions, showing evidence that no matter where someone is in their wellness journey, improvement and movement forward is a possibility. These results show that a focus on wellness should include all student demographics and not just ones that are in poor or fair health. While excellent health status students may have more tools readily available to continue their wellness journey moving forward, health educators should be mindful that education on these matters plays just as much a role in moving them forward as it does individuals in a lesser health status.

In summary, as health educators it is our job to take students from where they are (excellent or poor) in health status and attempt to move them forward on the health continuum as Travis $(1981 ; 2004)$ has pointed out. Through education on the matters of the 12 dimensions of wellness we can help plant seeds of health and wellbeing for future generations even after graduation.

\section{LIMITATIONS}

Some of limitations of this study are that there was no control group to see if these differences are the result of the physical education course or if it is just a natural occurrence of being in college. It is recommended that future studies adopt an experimental or quasi-experimental approach by including a control group that is not exposed to a physical education course. It is also recommended to try to capture pre-physical education students for an assessment and to 
potentially follow them for longitudinal data collection from the semesters where they have not taken a physical education course to the semester where they were taking a physical education course. Ambitious researchers could also consider tracking students longitudinally after a physical education course to see if trends were sustained across the college years. Another limitation, like many survey-based projects, is that the data were based on student selfreports with the potential for contamination through skewed information. However, the changes on most demographics may indicate that $1,000+$ students is probably a sufficiently large sample to reduce any effects of misreporting ratings of wellbeing. Another suggestion would be to try this same type of educational protocol with individuals in the general public to see if these matters of wellness show changes, when individuals are not required to do the work as in the form of class work for course credit.

\section{CONCLUSION}

Current trends in college student health are showing an increase in sedentary lifestyles for both college students and adults after graduation. It is important that colleges and universities offer courses in physical education and wellbeing to help lay the foundation of effective and healthy living after leaving college. Setting a foundation for effective health and wellness habits in college may influence lifestyle behaviors across the lifespan. With current research and trends showing that sedentary lifestyle correlates with negative health and illness consequences it is imperative that we as health educators provide the knowledge to students of what effective healthy behaviors are as well as what unhealthy behaviors look like. It is recommended health educators emphasize the importance of a more holistic approach to wellbeing and not only focus physical activity and eating well. This would include instructional materials and practices beyond the classroom that help to promote students to build a lifelong habit of health and wellness. Moving college students towards the direction of wellness as indicated in John Travis's Wellness Continuum can help set the tone for healthy future adults. 


\section{REFERENCES}

American College Health Association (ACHA; 2018). National College Health Assessment II: Undergraduate Student Reference Group Data Report. Available at: https://www.acha.org/documents/ncha/NCHA-

II_Spring_2018_Undergraduate_Reference_Group_Executive_Summary.pdf Accessed: April 1, 2019.

American College Health Association (ACHA; 2010). Healthy Campus 2010: Make it happen. Baltimore, MD

Baldwin, D., Towler, K., Oliver, M., \& Datta, S. (2017). An examination of college student wellness: A research and liberal arts perspective. Health Psychology Open, 1. https://doi.org/10.1177/2055102917719563

Buckworth, J., \& Nigg, C. (2004). Physical activity, exercise, and sedentary behavior in college students. Journal of American College Health. 53, 28-34. https://doi.org/10.3200/JACH.53.1.28-34

Burris, M., Brechting, M., Salsman, \& Carlson C. (2009). Factors associated with the psychological wellbeing and distress of university students. Journal of American College Health, 5, 536-544, https://doi.org/10.3200/JACH.57.5.536-544

Cardinal, B. (2014). Physical activity psychology research: where have we been? Where are we Going? Kinesiology Review, 3(1), 44-52. https://doi.org/10.1123/kr.2014-0036

Cardinal, B., Park, E., Kim, M., \& Cardinal, M. (2015). If exercise is medicine, where is exercise in medicine? Review of U.S. medical education curricula for physical activity-related content. Journal of Physical Activity \& Health, 12(9), 1336-1343. https://doi.org/10.1123/jpah.2014-0316

Downes, L. (2015). Physical activity and dietary habits of college students. The Journal of Nurse Practitioners, 11(2), 192-98. https://doi.org/10.1016/j.nurpra.2014.11.015

Edelman, C.L., Mandle, C.L. (9 $9^{\text {th }}$ eds). (2017). Health promotion throughout the lifespan. $9^{\text {th }}$ ed. St. Louis: Mosb

Engel, G. (1977). The need for a new medical model: A challenge for biomedicine. Science, 196, 129-136. https://doi.org/10.1126/science. 847460

Engel, G. (1980). The clinical application of the biopsychosocial model. American Journal of Psychiatry, 137, 535-544. https://doi.org/10.1176/ajp.137.5.535

Errisuriz V, Golaszewski N, Born K, \& Bartholomew J. (2018). Systematic review of physical education-based physical activity interventions among elementary school children J of Primary Prevention, 39(3), 303-327. https:/ /doi.org/10.1007/s10935-018-0507-x

Gieck, M., \& Olsen, M. (2007). Holistic wellness as a means to developing a lifestyle approach to health behavior among college students. Journal of American College Health, 56(1), 29-36. https://doi.org/10.3200/JACH.56.1.29-36

Gordon, J.S. (1990). Holistic medicine and mental health practice: Toward a new synthesis. American Journal of Orthopsychiatry, 60(3), 357-369. https://doi.org/10.1037/h0079185

Hettler, B. (1984). Wellness: Encouraging a lifetime pursuit of excellence. Health Values, 8, 13- 17. 
Hultquist, C., Duckham, R., Stinson, C., \& Thompson, D. (2009). College physical activity is related to mid-life activity levels in women. Journal of Exercise Physiology-online (JEPonline), 12(4), 1-7

Keating, X., Guan, J., Pinero, J., \& Bridges, D. (2005). A meta-analysis of college students' physical activity behaviors. J American College Health, 54(2), 116-25. https://doi.org/10.3200/JACH.54.2.116-126

Keyes, C., Eisenberg, D., Perry, G., Dube, S., Kroenke, K., \& Dhingra, S. (2012). The relationship of level of positive mental health with current mental disorders in predicting suicidal behavior and academic impairment in college students. Journal of American College Health, 60, 126-132. https://doi.org/10.1080/07448481.2011.608393

Keyes, C., \& Grzywacz, J. (2005). Health as a complete state: The added value in work performance and healthcare costs. Journal of Occupational and Environmental Medicine, 47, 523-532. https://doi.org/10.1097/01.jom.0000161737.21198.3a

Keyes, C., \& Simoes, E. (2012). To flourish or not: Positive mental health and all-cause mortality. American Journal of Public Health, 102, 2164-2172. https://doi.org/10.2105/AJPH.2012.300918

Kirsten, T.G., Van der Walt, H.S.J.L., \& Viljoen, C.T. (2009). Health, wellbeing and wellness: An anthropological eco-systemic approach. Health SA Gesondheid, 14(1), 1-7. https://doi.org/10.4102/hsag.v14i1.407

Lothes, J., \& Nanney, L. (2019). Using the wellness inventory to assess health and wellbeing in college students at the end of the semester. Journal of American College Health, 1-8.

Lyubomirsky, S., King, L., \& Diener, E. (2005). The benefits of frequent positive affect: does happiness lead to success? Psychological Bulletin, 131, 803-885. https://doi.org/10.1037/0033-2909.131.6.803

Myers, J., \& Sweeney, T. (2004). The indivisible self: An evidence-based model of wellness. Journal Individual Psychology, 60, 234-244.

Nanney. (2019). Physical activity and wellness. TopHat: Toronto Canada.

Prilleltensky, I., Dietz, S., Prilleltensky, O., Myers, N., Rubenstein, C., Jin, Y., \& McMahon, A. (2015) Assessing multidimensional wellbeing: Development and validation of the I-COPPE scale. Journal of Community Psychology, 43(2), 199-226. https://doi.org/10.1002/jcop.21674

Rouse, P., \& Biddle, S. (2009). An ecological assessment of the physical activity and sedentary behavior patterns of university students. Journal of Health Education, 69(1), 116-125. https://doi.org/10.1177/0017896910363145

Steptoe, A., Deaton. A., \& Stone, A. (2015). Subjective wellbeing, health, and ageing. The Lancet, 385, 640-648. https://doi.org/10.1016/S0140-6736(13)61489-0

Travis, J.W. (1981). The Wellness Inventory. Mill Valley, CA. Wellness Associates

Travis J.W., \& Ryan R.S. (1981). Wellness workbook $1^{\text {st }}$ ed. Berkeley: Ten Speed Press.

Travis J.W., \& Ryan R.S. (1988). Wellness workbook. $2^{\text {nd }}$ ed Berkeley: Ten Speed Press.

Travis J.W., \& Ryan R.S. (2004). Wellness workbook $3^{\text {rd }}$ ed. Berkeley: Ten Speed Press. 
US Department of Health and Human Services. (DHHS; 2019). Physical activity guidelines for Americans. 2 nd ed. Washington, DC: US Government Printing Office.

Wahl-Alexander, Z., \& Chomentowski, P. (2018). Impact of a university physical conditioning sports education season on student' fitness levels. Health Education Journal, 21, 1-9. https:/ / doi.org/10.1177/0017896918776340

World Health Organization. (WHO; 2010). Global recommendations on physical activity for health. Switzerland

Author Correspondence may be addressed to:

John Lothes II, LPA, Ed.D.

Lecturer

University of North Carolina Wilmington

School of Health and Applied Human Sciences

Physical Activity and Wellness (PED 101)

601 S. College Rd.

Wilmington, NC 28403

lothesj@uncw.edu

\section{Conflict of Interest Disclosure}

The author has no conflicts of interest to report. The author confirms that the research presented in this article met the ethical guidelines, including adherence to the legal requirements, of the United States and received approval from the Institutional Review Board of the University of North Carolina Wilmington (18-0232). 